\title{
Размышления о волонтерстве в видеоблогосфере: возможности участия в принятии социально значимых решений
}

\section{Введение}

Видеоблогинг на сегодняшний день является крупным и серьезным каналом воздействия на аудиторию. Видеоблогеры формируют потребительские предпочтения своих зрителей, являясь лидерами мнений. Идеи, нормы и ценности, которые они транслируют, влияют на ценностные установки аудитории, в особенности молодежи и подростков. Они также оказывают влияние на общественное мнение по самым разнообразным вопросам, в том числе связанным с продвижением общественных или политических инициатив. Сами авторы видеоблога далеко не всегда отдают себе в этом отчет. Видеоблогинг сегодня становится инструментом интернет-маркетинга, эфофективным способом продвижения товаров и услуг. Чтобы лучше понимать, чего ждать от подрастающего поколения, и иметь возможность прогнозировать будущую модель его поведения, важно следить за деятельностью популярных видеоблогеров [2].

Видеоблогинг - это одна из форм досуга современной молодежи, заменившая телевидение. Последнее, согласно ряду исследований, теряет популярность у молодых людей. Эту нишу занимают платформы для обмена видео, такие, к примеру, как YouTube. Молодые люди смотрят забавные ролики, различные обучающие видео, а также видео популярных видеоблогеров. При әтом пользователь не ограничен временными рамками показа телепередач, а для просмотра ему достаточно мобильного устройства, имеющего выход в Интернет [1].

Исследователи постепенно осваивают тему видеоблогинга. Обзор публикаций наглядно демонстрирует рост популярности тематики видеоблогов в научной среде. Если до 2017 года встречались единичные работы отечественных исследователей о влогах и влогерах, и большая часть исследовательской практики принадлежала зарубежным авторам, то начиная с 2017 года количество тематических публикаций, как зарубежных, так и российских, выросло в разы. При поиске публикаций в научной электронной библиотеке elibrary. ru на тему видеоблогинга с ограничением по дате выхода 2000-2017 гг. было найдено 60 источников. Однако продление временного диапазона до 2020 года позволило обнаружить уже более 200 публикаций по данной тематике.

Как и отечественные исследователи, зарубежные авторы уделяют внимание интернет-блогам в целом, без выделения детского сегмента и за-

\author{
(C) Абросимова E. E., Филипова А. Г., 2020
}

АБРОСИМОВА Евгения Евгеньевна, канд. социол. наук, начальник отдела организации научно-исследовательской работы Владивостокского государственного университета экономики и сервиса (2. Владивосток). E-mail: gaijony@mail.ru

ФИЛИПОВА А.Г., д-р социол. наук, зав. лабораторией комплексных исследований детства Владивостокского государственного университета экономики и сервиса (г. Владивосток). E-mail: alexgen77@list.ru 
трагивают следующие темы: проблемы конфиденциальности информации видеоблогов (Fernanda B. Viégas); структура видеоблогосфереры (K. Dean), coобщества видеоблогеров на канале YouTube (A. Mogallapu), социальная активность видеоблогеров (B.A. Nardi, D.J. Schiano, M. Gumbrecht), жанровый анализ видеоблогов (S.C. Herring, L.A. Scheidt, S. Bonus).

Однако волонтёрство в видеоблогосфере - тема, недостаточно изученная как у нас, так и за рубежом. Авторы анализируют видеоблоги как канал коммуникации, предпринимаются попытки классификации видеоблогов изучается образовательный потенциал видеоблогов $[\mathbf{5}, \mathbf{9}, \mathbf{1 3 ]}$.

Волонтёрство, как и другие социальные явления (образовательные процессы, политическая борьба и пр.), постепенно проникает в видеоблогосфреру. Ряд известных видеоблогеров, осознавая популярность волонтёрства, а также фракт положительной оценки зрителями данного видеоконтента, все больше приобщаются к добровольческой деятельности.

Большое количество социальных роликов о волонтёрстве создаются различными общественными организациями благотворительной направленности. Многие видеоролики размещаются на интернет-ресурсах, принадлежащих непосредственно организациям, но параллельно с целью популяризации и продвижения добровольческой деятельности подобного рода ролики размещаются на канале YouTube.

\section{Методы и материалы}

В рамках исследования была организована подборка видеоблогов и видеороликов на тему волонтёрства. Отбор осуществлялся на самой популярной видеохостингговой платформе - YouTube. В условиях обилия информации и дефицита времени людям гораздо проще смотреть картинки и видео, чем вникать в смысл написанного. Поэтому YouTube сегодня это - максимально удобный и доступный источник визуальной информации, в том числе и о волонтёрстве.

Традиционно, поиск на YouTube начинается с введения ключевых слов. В нашем случае выбор пал на несколько позиций: волонтёрство, волонтёр и доброволец. Отбор был произведен 15 августа 2020 года. Фиксация точного времени отбора важна, так как изменение рейтинга видеоблогеров и видеоблогов происходит очень быстро. Следует отметить, что поисковый сервис YouTube организован таким образом, что верхние строки поиска могут занимать как видео с большим количеством просмотров, так и менее популярный видеоматериал. Всего было отобрано 10 видеороликов и видеоблогов (влогов). Под видеоблогом понимается систематически и регулярно выкладываемое в интернет авторское видео, которое не только подходит под какое-либо жанрово-тематическое направление, но и содержит "личностный" компонент. Видеоролик часто содержит исключительно информационный контент и не привязан к личности автора [2].

Помимо вышеуказанных параметров отбора нами был применен дифференцированный подход к видеороликам и видеоблогам. Учитывая "личностный компонент" видеоблогов, мы остановили свой выбор на контенте, который является популярным среди зрителей благодаря авторскому вкладу. Также мы включили в выборку ролики, созданные с информационной целью, так как они реализуют функцию популяризации волонтёрства.

Анализ видеоблогов и видеороликов осуществлялся по следующим параметрам: название, краткое содержание, автор, дата загрузки, количество просмотров, количество лайков, количество комментариев [2].

Для получения обратной связи от пользователей видеоблогов нами были организованы групповые дискуссии в двух студенческих группах на базе Владивостокского государственного университета экономики и сервиса. Общее количество участников составили 25 человек в возрасте от 18 до 23 лет. Участникам задавались вопросы относительно их включенности в волонтёрскую деятельность, влияния видеоблогосферы на отношение к волонтёрству, мотивационном потенциале влогов и пр. Отдельно участники исследования выполняли индивидуальные задания - просматривали два видеоролика о волонтёрстве и отвечали на вопросы. 
Ключевым исследовательским вопросом стал вопрос о возможности волонтёрства и волонтёров оказывать влияние/участвовать в принятии социально значимых решений через видеоблогосферу.

\section{Результаты и их обсуждение. Видеоролики и видеоблоги о волонтёрстве}

Отобранные видеоролики условно были разделены нами на две группы - ролики, подготовленные организациями и индивидуальные ролики (видеоблоги).

Первая группа - официальные видео - носят в большей мере информационный характер. Они ориентированы на тех, кто заинтересовался волонтёрством как деятельностью, в т.ч на профессиональном уровне. $К$ примеру, ролик "Я - волонтер", подготовленный организацией "Перспективы", г. Санкт-Петербург, рассказывает о том, зачем нужны волонтёры и кто они такие. Канал "Школа социального волонтёрства" содержит целую серию видео, направленных на обучение волонтёров, повышение их квалификации, подготовку координаторов и руководителей волонтёрских групп и сообществ. Фонд "Подари жизнь" - организация, чья деятельность направлена на помощь детям с онкологическими, гематологическими и иными тяжелыми заболеваниями, снимает ролики о волонтёрах в юмористическом ключе, что является дополнительным мотивирующим фрактором для зрителей $[11, \mathbf{1 4}, \mathbf{1 5}]$.

Вторая группа роликов условно обозначена нами как "индивидуальные". Они отличаются тем, что содержат личный опыт людей, в основном авторов видео, о волонтёрской деятельности. Так же, как и ролики первой группы, индивидуальные ролики имеют мотивационную направленность и пропагандируют добровольческую деятельность. Так, видеоканал "Всего и Побольше" в ролике "США. Я Волонтер в Больнице! Вечеринка" рассказываете об опыте волонтёрства обычной девушки Марии, которая живёт в Калифорнии. Канал "Maria From Miami" тоже повествует о волонтёрской деятельности в США и тоже глазами девушки из России [6, 7].

Следует отметить, что анализ данного сегмента видеоблогосферы показал, что из 5 "индивидуальных" роликов о волонтёрстве, попавших в нашу выборку, 3 ролика связаны с США. Ряд каналов созданы нашими соотечественниками, часть - гражданами США. Это обусловлено тем, что Соединенные Штаты - одна из стран-лидеров по количеству волонтёров и развитости благотворительной деятельности $[8,12,16]$.

Распространение волонтёрства обязано не только деятельности правительства по поддержке различных программ, но и активности медийных лиц, чье мнение значимо для современной молодежи. Среди видеороликов нашей выборки можно отметить только один видеоролик, который напрямую связан с демонстрацией волонтёрства. Видеоблогер Dava снял видеоролик "Брошены, но не забыты. Я волонтер" о помощи пожилым людям в период пандемии [4].

В рамках анализа видеороликов мы остановились на нескольких представителях каждой из двух групп. Очевидно, что популярные и доступные видеоролики имеют большее значение для зрителей. Во-первых, это те ролики, которые пользователь посмотрит в первую очередь, во-вторых, современная молодежь уделяет значительное внимание рейтингу видеоконтента. В таблище 1 приведены количественные характеристики индивидуальных видеороликов о волонтёрстве.

Ролик "США us Я ВОЛОНТЕР в Больнице! ВЕЧЕРИНКА" повествует о том, каково это быть волонтёром в американской больнице. Автор видео демонстрирует положительные аспекты благотворительной деятельности в США, например, приглашение в ресторан на вечеринку волонтёров. Своим примером автор показывает, что волонтёр осуществляет значимую социальную фонкцию в обществе. Ролик снят в стиле "life style", что также приветствуется молодыми зрителями и способствует восприятию информации.

Ролик "Грин Кард за волонтёрство в США?! Плюсы волонтёрства! Что даст вам бесплатная работа?" тоже направлен на описание "плюсов" волонтёрской деятельности в Америке. Он носит более официальный, чем предыдущее видео характер, более информативен. 
Таблица 1. Индивидуальные видеоролики

\begin{tabular}{|l|c|c|c|c|c|}
\hline \multicolumn{1}{|c|}{ Название видео } & $\begin{array}{c}\text { Название } \\
\text { видеоканала }\end{array}$ & $\begin{array}{c}\text { Дата } \\
\text { создания }\end{array}$ & $\begin{array}{c}\text { Количество } \\
\text { просмотров }\end{array}$ & $\begin{array}{c}\text { Количество } \\
\text { лайков }\end{array}$ & $\begin{array}{c}\text { Количество } \\
\text { комментариев }\end{array}$ \\
\hline $\begin{array}{l}\text { США из Я ВОЛОНТЕР в } \\
\text { Больнице! ВЕЧЕРИНКА }\end{array}$ & Всего и Побольше & 27.04 .2019 & 7695 & 332 & 209 \\
\hline $\begin{array}{l}\text { Грин Кард за волонтёр- } \\
\text { ствО в США?! Плюсы } \\
\text { волонтёрства! Что даст } \\
\text { вам бесплатная работа? }\end{array}$ & Maria From Miami & 18.062018 & 10337 & 843 & 107 \\
\hline $\begin{array}{l}\text { Волонтёрство в США. } \\
\text { Благотворительность в } \\
\text { Америке }\end{array}$ & $\begin{array}{c}\text { We've all been there } \\
\text { СОMEDY }\end{array}$ & 2.03 .2020 & 108 & 17 & 7 \\
\hline $\begin{array}{l}\text { Стала Волонтером \#МЫ- } \\
\text { ВМЕСТЕ2020: Что делают } \\
\text { волонтеры во время } \\
\text { карантина в России? }\end{array}$ & Polina Eхреrience & 6.04 .2020 & 3419 & 152 & 82 \\
\hline $\begin{array}{l}\text { Почему тебе стоит попро- } \\
\text { бовать волонтёрство }\end{array}$ & Elisabethveto & 20.09 .2019 & 887 & 34 & 1 \\
\hline
\end{tabular}

Источник: составлено авторами

Видео "Волонтёрство в США. Благотворительность в Америке" рассказывает о том, где "волонтёрят" американцы, как они помогают нуждающимся и зачем они занимаются благотворительностью. Автор также акцентирует внимание на потенциальных бонусах добровольческой деятельности молодых людей для будущей карьеры.

Из отобранных видеороликов второй группы единственный ролик про волонтёрство в России - "Стала Волонтером \#МЫВМЕСТЕ2020: что делают волонтёры во время карантина в России?". Ролик снят в стиле "life style". Автор делится опытом волонтёрства в период пандемии и объясняет свой выбор тем, что она имеет достаточно крепкий иммунитет и хочет помогать пожилым людям, оказавшимся в условиях самоизоляции.

Анализируя количественные показатели, можно выделить два видео, которые наиболее популярны у зрителей. Это видео каналов "Всего и Побольше" - 7695 просмотров и "Maria From Miami" - 10337 просмотров. Также эти видео лидируют и по количеству комментариев. Большинство комментариев оставляют молодые люди.

Комментарии носят позитивный характер, многие пользователи благодарят авторов за полезную информацию, некоторые просто говорят комплименты за интересный и полезный видеоконтент: "супер полезная инфборлаиия! Спасибо Мария"; "спасибо, интересная инфборлаиия и классная идея пойти волонтерол туда, куда хотелось бы попасть в дальнейшел"; "я бы хотел в приюте для животньх поработать!"; "да, занилаться волотерствол - это действительно салое хорошее дело в мире!!! Пологать окружаюшил! Полощь людял, животныл, обществу, однил словол вселу миру!!! Спасибо Вали за волонтерство!!!".

Комментарии отражают тот фракт, что пользователи оценивают волонтёрскую деятельность как важный этап в принятии социально значимых решений. Волонтёрство - не просто дань моде или процесс одностороннего включения, волонтёрство - это возможность "помогать нуждающимся и менять мир в лучшую сторону".

Меньший количественный отклик в сети получили те видео (что вполне естественно), которые были значительно позже размещены в сети.

В таблице 2 приведены количественные характеристики видеороликов о волонтёрстве, подготовленных организациями.

Видеоролики, которые создаются организациями, менее популярны, чем ролики другой группы. Несмотря на более раннюю дату создания, часть роликов имеет очень небольшое количество комментариев. Это отражает основную фонкцию роликов, созданных организациями - информационную. 
Таблица 2. Видеоролики организаций

\begin{tabular}{|l|c|c|c|c|c|}
\hline \multicolumn{1}{|c|}{ Название видео } & $\begin{array}{c}\text { Название } \\
\text { видеоканала }\end{array}$ & $\begin{array}{c}\text { Дата } \\
\text { создания }\end{array}$ & $\begin{array}{c}\text { Количество } \\
\text { просмотров }\end{array}$ & $\begin{array}{c}\text { Количество } \\
\text { лайков }\end{array}$ & $\begin{array}{c}\text { Количество } \\
\text { комментариев }\end{array}$ \\
\hline Я-волонтер & $\begin{array}{c}\text { Организация } \\
\text { "Перспекивы" } \\
\text { Санкт-Петербург }\end{array}$ & 21.07 .2016 & 21671 & 217 & 8 \\
\hline $\begin{array}{l}\text { Социальный ролик } \\
\text { "Волонтеры КиноАка- } \\
\text { демии" }\end{array}$ & $\begin{array}{c}\text { Всероссийский детский } \\
\text { оздоровительно-об- } \\
\text { разовательный центр } \\
\text { "Смена" }\end{array}$ & 25.082018 & 935 & 21 & 1 \\
\hline $\begin{array}{l}\text { Стать волонтёром: с } \\
\text { чего начать? }\end{array}$ & $\begin{array}{c}\text { Школа социального } \\
\text { волонтерства }\end{array}$ & 23.05 .2016 & 11162 & 263 & 33 \\
\hline $\begin{array}{l}\text { Один день из жизни } \\
\text { волонтера }\end{array}$ & Фонд "Подари жизнь" & 5.12 .2012 & 5850 & 78 & 5 \\
\hline $\begin{array}{l}\text { Почему быть волонте- } \\
\text { ром круто? }\end{array}$ & Свежий Взгляд & 4.12 .2018 & 264251 & 1800. & 78 \\
\hline
\end{tabular}

Источник: составлено авторами

Зритель приходит за информацией, получает её и на этом все заканчивается, диалога не происходит.

С персонифицированными роликами дела обстоят немного по-другому. Автор видео не всегда освещает в своем видеоблоге только благотворительность и волонтёрство. Жизненные влоги интересны зрителям в основном из-за личности самого автора. И если он занимается волонтёрством, то это поднимает его рейтинг, с одной стороны, и мотивирует к такой деятельности его зрителей, с другой.

Очевидно, что специально за информацией о волонтёрстве в сеть приходят люди, которые уже приняли решение стать добровольцем, или, как минимум, обладают какого-то рода информацией. Тогда для них полезнее и продуктивнее обращаться к видео соответствующих организаций.

Зрители же личных влогов в большей степени получают добровольческий стимул от своих кумиров, которые готовы помогать людям. Среди медийных личностей, пропагандирующих волонтёрство и благотворительность, не только популярные видеоблогеры, но и другие известные личности. Так, актёр и режиссёр Константин Хабенский на своем личном канале рассказывает о благотворительности и волонтёрстве [3]. Наталья Водянова, российская киноактриса и супермодель, является примером активного добровольчества, о чем и рассказывает в своем видео [10]. Ролики известных людей достаточно сильно мотивируют пользователей к включению в благотворительную деятельность, а также дают зрителям понять, что волонтёрство является одной из возможностей влиять на принятие социально значимых решений.

Положительный пример, дополненный полезной информацией, способствует распространению волонтёрских практик как повседневных практик в жизни современных подростков и молодежи.

\section{Волонтёрство и видеоблоги: обратная связь}

Обратная связь по поводу видеоблогов и видеороликов о волонтёрстве была получена от студентов Владивостокского государственного университета экономики и сервиса в ходе групповых обсуждений и выполнения студентами индивидуальных заданий.

Предварительно полученные данные демонстрируют в целом положительное отношение студентов к видеоблогосфере, видеоблогам и видеороликам о волонтёрах и т.п. Это неоднократно отмечают участники группового обсуждения:

Освещение волонтерали проблель в интернете, да еще и в визуальной (видео) фборме может привлечь внимание к социальныл проблемал (Лиза, 21 год) 
Для детей-подписчиков видеоблогов важен личный прилер видеоблогера: Если любилый блогер ребёнка скажет, что волонтерство это круто и полезно, то он будет считаться с его мнениел. На своём прилере блогерь показывают, как важно пологать людял. (Люба, 20 лет)

Участники дискуссии в большей степени говорили о социальных роликах, созданных для информирования аудитории о возможностях включения в добровольческую деятельность:

Узнать контакты волонтёрских организаций, понять интересно ли ил это или нет, и какие трудности и обязанности их ждут впереди (Юля, 20 лет).

Видеоблоги могут быть ответали на некоторые вопросы тех, ктохочет заняться волонтерствол, но ничего еще не знает (Юля, 21 год).

Однако студенты также говорили о рекламном характере видеороликов, самопиаре видеоблогеров за счет демонстрации собственного включения в социально значимую деятельность:

Многие используют это для собственного самоудовлетворения и выгоды (Елена, 22 года).

В качестве индивидуального задания студентам предлагалось сравнить два видеоролика о волонтёрстве. Первый ролик "МЫВМЕСТЕ2020" - из группы индивидуальных, второй "Я-волонтер" - создан организацией $[6,15]$. Участникам исследования предлагалось сравнить их, оценить мотивирующее воздействие каждого и возможность волонтёров участвовать в принятии социально значимых решений.

Относительно индивидуального ролика респонденты подчеркивали его информативность, эмоциональную сдержанность, личный пример автора:

Для меня более мотивирующим оказался ролик "МЫВМЕСТЕ2020", так как в отличие от первого он менее элоциональный, более инфорлативный и конкретный. На прилере девушки можно проследить, что пологать другил совсел не сложно, но очень полезно. Также видео содержит прилерную инбборлацию о тол, куда ложно обратиться для волонтерства во время пандемии, какие есть особые указания и правила (Екатерина, 19 лет).

Интересно наблюдать за салил проиессол, так сказать, узнавать всё изнутри от салого волонтёра, как они осуществляют полощь (Света, 18 лет).

То есть в первом ролике видна личность автора, ролик персонифицирован, автор показывает "кусочек" своей жизни. Кроме того, студенты-участники исследования интерпретируют действия видеоблогера как его личный выбор и возможность оказывать влияние на принятие социально значимых решений:

Девушка рассказывает, что приняла это решение сала, что это не так сложно вынести лусор, купить продукты, зато вы делаете добро людям и получаете большую благодарность взален (Света, 18 лет).

Другой респондент, подчеркивая участие волонтёра из первого ролика в принятии социально значимых решений, аргументирует:

Возложность определенного принятия решений у волонтеров проявляется в большей степени в первол ролике, так как в нел показан прилер изленяюшихся условий средь (на прилере панделии коронавируса), и даже сала девушка в нел говорит о тол, как можно было бы модернизировать способ помощи нуждающился людям (наприлер, делать заказы у доставщиков или заранее собирать заказы) (Марина, 18 лет).

То есть волонтёры, будучи вовлечены в деятельность по оказанию помощи нуждающимся, могут дать дельные советы по ее совершенствованию.

Еще один участник исследования - Ольга (20 лет) так объясняет возможность волонтёров участвовать в принятии социально значимых решений: Эта возложность, в первую очередь, выражается в салол решении, помогать или не пологать (то есть, быть ли волонтёрол), зател в выборе конкретной сфберы, где пологать хочется и кажется наиболее важныли, а также в принятии решения, как иленно полочь. Хотя в первол видео приводился пример "реглалентированной" полощи, всё же приходилось подулать, наприлер, как достать недоступные парацеталол и маски. 
Мария (19 лет), демонстрируя собственную осведомленность о современных влогерах (блогер Дава Манукян; телеведущая и блогер Настя Ивлеева; блогер и модель Ника Вайпер; российская телеведущая и видеоблогер Ида Галич; модель, блогер и актриса Карина Кросс), заключает:

Сегодня каждый видеоблогер занилается благотворительностью. Не будел делать поспешных выьводов, с чел это связано. Но хочется верить, что всё идет от чистого сердиа, а не ради пиара и общественного мнения, дабы показать свою значилость.

Другая часть участников исследования, высказываясь в пользу второго ролика, отмечают его эмоциональную насыщенность:

Элоционально он более ярок и заставляет проникнуться судьбой этих детей. В особенности на это влияет то, что он короткий, в нел сказана самая важная инбборлация, а также используется элоциональная песня, что также способствует проявлению элпатии со сторонь зрителя (Марина, 18 лет).

Продессиональные видеоролики как раз и отличаются от любительских сильным эмоциональным воздействием благодаря хорошо продуманному сценарию, музыкальному оформлению, выбранным действующим лицам и пр. Хотя подобный профессионализм может стать отталкивающим фрактором, как, например, в случае с Анастасией (19 лет). Студентка сравнивает два видеоролика:

Первый ролик (ролик Полинь) мотивирует сильнее, ведь девушка говорит от себя, рассказывает всё как есть, не завлекает, пытаясь вызвать эмоции жалости и сочувствия, а конкретно и доступно объясняет, что приходится делать волонтёрал, и проявляет свои эмоиии, говорит о своих чувствах. А вот второе видео кажется несколько манипулятивныли, оно способно растрогать до слёз, но иленно это отталкивает, создаётся впечатление, что "делать добро" навязывают.

\section{Выводы}

Видеоблогосфера стала неотьемлемой частью повседневной жизни современной молодежи, а видеоблогеры стали такими же популярными медийными личностями, как телеведущие и артисты. Видеоблогеры и видеоблогинг оказывают мощное воздействие на молодых людей, при этом воздействие может быть, как созидательным, направленным, к примеру, на вовлечение в волонтёрство, так и разрушительным, провоцирующим пользователей на опасные эксперименты. Мы обращаемся к позитивной стороне видеоблогинга, мотивирующей аудиторию к вовлечению в социально значимую деятельность, оказание помощи нуждающимся.

Можно констатировать огромный потенциал видеоблогосферы в привлечении внимания аудитории к решению социально значимых проблем, в том числе через участие молодежи в волонтёрской деятельности.

Видеоролики о волонтёрстве, профессиональные и любительские, обладают разным по силе эмоциональным и мотивирующим воздействием на аудиторию. На пользователей более сильное влияние оказывают видеоролики, максимально приближенные к жизни, с одной стороны, а с другой - ролики, в которых присутствует медийная личность - известный видеоблогер, актер, телеведущий и т.п. Срабатывает эффект вовлеченности в чужую жизнь, в данном случае - жизнь видеоблогера, показывающего на собственном примере, что можно сделать, чтобы изменить мир в лучшую сторону. Возможность волонтёра участвовать в решении социально значимых вопросов начинается с принятия собственного решения о волонтёрстве, выборе конкретной сферы волонтёрства, и продолжается в практических действиях на этом пути и действиях по улучшению добровольческой работы. Любой волонтёр, погрузившись в свою работу, начинает понимать, как можно ее улучшить, сделать более продуктивной, справиться с ситуацией в условиях ограниченности ресурсов (как, например, в случае с помощью пожилым в период пандемии). 


\section{Литература}

1. Абросимова Е.Е. Детский видеоблогинг. Детство XXI века: социогуманитарный тезаурус. Тематический словарь-справочник. М.: Российское общество социологов, 2018. С. 309-313.

2. Абросимова Е.Е., Филипова А.Г., Ардальянова А.Ю. Видеоблогинг глазами детей и взрослых: социологический анализ. СПб.: Астерион, 2019. 230 с.

3. Актёр и режиссёр Константин Хабенский о благотворительности и волонтёрстве. [Электронный ресурc]. URL: https://www.youtube.com/watch?v=BGWa_A6hOeo (дата обращения: 3.10.2020).

4. Брошены, но не забыты. Я волонтер. [Электронный ресурс]. URL: https://www. youtube.com/watch?v=Ijvw5QjtVvA (дата обращения: 3.10.2020).

5. Бычкова М.Б. Современный видеоблог: причины популярности и жанровое многообразие // Вестник Тверского государственного университета. Серия: Филология. 2019. № 1 (60). C. 127-131.

6. Видеоблог Polina Experience. [Электронный ресурc]. URL: https://www.youtube. com/watch?v=aPLBMJjsSR0 (дата обращения: 3.10.2020).

7. Видеоблог The Alice Twins. [Электронный ресурc]. URL: https://www.youtube. com/watch?v=Fypw3nMxdUQ (дата обращения: 3.10.2020).

8. Капранов Г.А. Волонтерство в США // Воспитание школьников. 2010. № 2. C. $66-70$.

9. Мулюкова А.И. Видеоблогинг как средство интернет коммуникации // Всероссийская с международным участием научная конференция студентов и аспирантов "Слово и текст в культурном и политическом пространстве". Сыктывкар: ФГБОУ BО "Сыктывкарский государственный университет им. Питирима Сорокина", 2017. C. $270-271$.

10. Наталья Водянова о благотворительности. [Электронный ресурc]. URL: https:// www.youtube.com/watch?v=Evzx398YZYg (дата обращения: 3.10.2020).

11. Один день из жизни волонтера. [Электронный ресурc].URL: https://www. youtube.com/watch?v=OvAkLL5XkSQ\&t=62s (дата обращения: 5.10.2020).

12. Певная М.В., Кузьминчук А.А. Соџиологический анализ нормативно-правового регулирования волонтерства в США и России // Известия Уральского федерального университета. Серия 1: Проблемы образования, науки и культуры. 2014. Т.-126. № 2. C. 131-139.

13. Середа П. В. Видеоблог как способ развития навыков аудирования при обучении иностранному языку // Электронный сетевой политематический журнал "Научные труды КУБГТУ". 2017. № 2. С. 276-281.

14. Стать волонтёром: с чего начать? [Электронный ресурc]. URL: https://www. youtube.com/watch?v=BEdxJO_tSZM\&t=70s (дата обрашения: 15.09.2020).

15. Я - волонтер. [Электронный pecypc]. URL: https://www.youtube.com/ watch?v=v2PDrZCdLHs (дата обращения: 15.09.2020).

16. The most generous state in America. By Thom Patterson. [Электронный ресурс]. URL: https://us.cnn.com/2019/06/04/us/volunteering-statistics-united-states-america-cfc/ index.html (дата обращения: 5.10.2020).

\section{Транслитерация по ГОСТ 7.79-2000 Система Б}

1. Abrosimova E.E. Detskij videobloging. Detstvo XXI veka: sotsiogumanitarnyj tezaurus. Tematicheskij slovar'-spravochnik. M.: Rossijskoe obshhestvo sotsiologov, 2018. S. 309-313.

2. Abrosimova E.E., Filipova A.G., Ardal'yanova A.YU. Videobloging glazami detej i vzroslykh: sotsiologicheskij analiz. SPb.: Asterion, 2019. 230 s.

3. Aktyor i rezhissyor Konstantin KHabenskij o blagotvoritel'nosti i volontyorstve. [EHlektronnyj resurs]. URL: https://www.youtube.com/watch?v=BGWa_A6hOeo (data obrashheniya: 3.10 .2020 ).

4. Brosheny, no ne zabyty. YA volonter. [EHlektronnyj resurs]. URL: https://www. youtube.com/watch?v=Ijvw5QjtVvA (data obrashheniya: 3.10.2020).

5. Bychkova M.B. Sovremennyj videoblog: prichiny populyarnosti i zhanrovoe mnogoobrazie // Vestnik Tverskogo gosudarstvennogo universiteta. Seriya: Filologiya. 2019. № 1 (60). S. 127-131.

6. Videoblog Polina Experience. [EHlektronnyj resurs]. URL: https://www.youtube. com/watch? $\mathrm{v}=\mathrm{aPLBMJjsSR0}$ (data obrashheniya: 3.10.2020).

7. Videoblog The Alice Twins. [EHlektronnyj resurs]. URL: https://www.youtube. com/watch?v=Fypw3nMxdUQ (data obrashheniya: 3.10.2020). 70 .

8. Kapranov G.A. Volonterstvo v SSHA // Vospitanie shkol'nikov. 2010. № 2. S. 66-

9. Mulyukova A.I. Videobloging kak sredstvo internet kommunikatsii // Vserossijskaya s mezhdunarodnym uchastiem nauchnaya konferentsiya studentov $\mathrm{i}$ aspirantov 
"Slovo i tekst v kul'turnom i politicheskom prostranstve". Syktyvkar: FGBOU VO "Syktyvkarskij gosudarstvennyj universitet im. Pitirima Sorokina", 2017. S. 270-271.

10. Natal'ya Vodyanova o blagotvoritel'nosti. [EHlektronnyj resurs]. URL: https:// www.youtube.com/watch?v=Evzx398YZYg (data obrashheniya: 3.10.2020).

11. Odin den' iz zhizni volontera. [EHlektronnyj resurs].URL: https://www. youtube. $\mathrm{com} / \mathrm{watch}$ ? $\mathrm{v}=$ OvAkLL5XkSQ\&t=62s (data obrashheniya: 5.10 .2020 ).

12. Pevnaya M.V., Kuz'minchuk A.A. Sotsiologicheskij analiz normativno-pravovogo regulirovaniya volonterstva v SSHA i Rossii // Izvestiya Ural'skogo federal'nogo universiteta. Seriya 1: Problemy obrazovaniya, nauki i kul'tury. 2014. T.-126. № 2. S. 131-139.

13. Sereda P. V. Videoblog kak sposob razvitiya navykov audirovaniya pri obuchenii inostrannomu yazyku // EHlektronnyj setevoj politematicheskij zhurnal "Nauchnye trudy KUBGTU". 2017. № 2. S. 276-281.

14. Stat' volontyorom: s chego nachat'? [EHlektronnyj resurs]. URL: https://www. youtube.com/watch?v=BEdxJO tSZM\&t=70s (data obrashheniya: 15.09.2020).

15. YA - volonter. [EḦlektronnyj resurs]. URL: https://www.youtube.com/ watch? $v=$ v2PDrZCdLHs (data obrashheniya: 15.09.2020).

16. The most generous state in America. By Thom Patterson. [EHlektronnyj resurs]. URL: https://us.cnn.com/2019/06/04/us/volunteering-statistics-united-states-america-cfc/ index.html (data obrashheniya: 5.10.2020).

Абросимова Е. Е., Филипова А. Г. Размышления о волонтерстве в видеоблогосфере: возможности участия в принятии социально значимых решений.

В статье представлен анализ двух современных явлений - волонтерства и видеоблогинга, точкой соединения которых стало участие молодежи в принятии социально значимых решений. Эмпирическим материалом для анализа стали индивидуальные видеоролики и видеоролики организаций, а также транскрипты двух молодежных фокус-групп и выполненные студентами индивидуальные задания на сравнение двух видеороликов. Полученные данные рассматриваются с точки зрения ресурсов видеоблогинга по вовлечению молодой аудитории в социально значимую деятельность, а также отражению в видеороликах возможности для волонтеров участвовать в принятии социально значимых решений. В ходе анализа выделены и сравниваются индивидуальные и организационные, профессиональные и любительские видеоролики о волонтерстве.

Ключевые слова: волонтерство, видеоблогинг, видеоблогер, участие в принятии социально значилых решений, молодежь

Abrosimova E. E., Filipova A. G. Reflections on Volunteering in the Video Blogosphere: Opportunities for Participation in Social Decision Making.

The article presents an analysis of two modern phenomena - volunteering and video blogging, the connecting point of which was the participation of young people in making socially significant decisions. The empirical material for the analysis was videos of two groups - individual videos and videos of organizations, as well as transcripts of two youth focus groups and individual tasks performed by students to compare the two videos. The obtained data are considered from the point of view of video blogging resources for engaging a young audience in socially significant activities, as well as reflecting in videos the ability of volunteers to participate in making socially significant decisions. The analysis highlighted and compared individual and organizational, professional and amateur videos about volunteering.

Key words: volunteering, video blogging, video blogger, participation in making socially significant decisions, youth

Для цитирования: Абросимова Е. Е., Филипова А. Г. Размышления о волонтерстве в видеоблогосфере: возможности участия в принятии социально значимых решений // Ойкумена. Регионоведческие исследования. 2020. № 4. С. 95-103. DOI: 10.24866/1998-6785/2020-4/95103

For citation: Abrosimova E. E., Filipova A. G. Reflections on Volunteering in the Video Blogosphere: Opportunities for Participation in Social Decision Making // Ojkumena. Regional researches. 2020. № 4. P. 95-103. DOI: 10.24866/1998-6785/2020-4/95-103 